\title{
O TÓPICO DISCURSIVO EM QUESTÃO: CONSIDERAÇÕES TEÓRICAS E ANÁLISE DE UMA NARRATIVA LITERÁRIA
}

\author{
RENATO CABRAL REZENDE* \\ (UNICAMP/CNPq)
}

\begin{abstract}
Considering the discourse topic concept and its distribution into two axes, hierarchical and linear, this paper aims at analysing both the distribution of topic units at the linear axis and the usage of textual connectives in the Sixth narrative of Relações, by Heleno Godoy. Having this short story as my object of study, I propose that these categories can contribute to the construction of a discursive phenomenon, that is, the discursive ethos of its narrator.
\end{abstract}

\section{CONSIDERAÇÕES INICIAIS}

Este artigo tem por objetivo discutir de que maneira unidades de natureza lingüísticodiscursiva, a saber, o tópico discursivo e alguns mecanismos de articulação textual, respectivamente, (i) distribuem-se no eixo seqüencial de organização tópica e (ii) operam na articulação destes tópicos visando a atuar na construção do ethos discursivo do narrador da Sexta narrativa de Relações, do escritor Heleno Godoy.

No entanto, meu trajeto não se restringirá a expor os conceitos mobilizados e articulá-los - o que não é tarefa fácil, ressalte-se - no fito de elaborar a análise tópica do texto em questão. Tendo como horizonte o tema desta edição especial, a saber, o tópico discursivo e os desdobramentos dos estudos desenvolvidos no Brasil pelo sub-grupo "Organização-textual interativa" do Projeto da Gramática do Português Falado (PGPF), entendo que um aspecto importante, de natureza teórico-metodológica, também requer discussão. Trata-se, observandose o eixo hierárquico de organização tópica, da diferença de concepção (e aplicação em análises) do conceito de Quadro Tópico (QT) presente em Jubran et al. (1992)1 ${ }^{1}$ Koch (1992) e Fávero (1993), pesquisadoras integrantes do sub-grupo da organização textual-interativa.

Isto posto, dedicarei a seção 3 deste artigo à apresentação da noção de Quadro Tópico nos referidos trabalhos para, à proporção em que efetuar a análise proposta, articular o conceito de ethos discursivo aos princípios teóricos de organização textual-interativa (seção 4).

\footnotetext{
* Doutorando em Lingüística (CNPq/ n 141963/2005-0), Universidade Estadual de Campinas (UNICAMP).

${ }^{1}$ Intitulado "Organização tópica da conversação", e publicado no volume II da Gramática do Português Falado, o texto é assinado pelos participantes do sub-grupo "Organização textual-interativa" PGPF. São eles: Clélia Cândida Abreu Spinardi Jubran, Hudinilson Urbano, Ingedore Grunfeld Villaça Koch, Leonor Lopes Fávero, Luiz Antônio Marcuschi, Luiz Carlos Travaglia, Maria Cecília Perez de Souza-e-Silva, Maria do Carmo Oliveira Turchiari Santos, Maria Lúcia da Cunha Victório de Oliveira Andrade, Mercedes Sanfelice Risso e Zilda Gaspar Oliveira de Aquino. A edição consultada para a redação deste trabalho é de 2002.
} 
REZENDE - O tópico discursivo em questão...

\section{O TÓPICO DISCURSIVO: UM CONCEITO GRADIENTE}

Antes de adentrar na questão do QT, é preciso traçar a linha teórica basilar ao trabalho das autoras supracitadas: a motivação textual-interativa na conceituação de tópico. Em trabalho pioneiro no Brasil, o sub-grupo "Organização-textual interativa" do PGPF, com o objetivo de definir uma categoria de estatuto discursivo para a análise de textos orais, propôs o tópico discursivo como esta categoria, tendo em vista atender a dois princípios: (i) que ela fosse uma unidade discursiva que, diferentemente da frase, considerasse fatores pragmático-contextuais inerentes às práticas comunicativas em geral; (ii) que fosse uma unidade com critérios sólidos o bastante para ser identificada e delimitada enquanto tal, tornando-se, assim, um dado objetivo, de modo a não ser entendida como sinônimo de "tema" ou "assunto".

Assim sendo, pode-se afirmar, em linhas gerais, que as autoras comungam a idéia de que o tópico discursivo é uma unidade abstrata e relacional, caracterizada pelas propriedades de centração ${ }^{2}$ e organicidade. Para depreender o(s) tópico(s) de um texto, o analista deve atentar tanto ao que concerne(m) este(s) tópico(s), a um "sobre o quê se fala", quanto a fatores lingüísticos e pragmático-contextuais que também atuam em sua estruturação interna e sua ocorrência no discurso.

A questão chave (e eis porque vem a calhar a propriedade da organicidade) reside no fato de o tópico discursivo ser uma noção gradiente, organizada hierarquicamente: quando falamos/ escrevemos, fazemo-lo dispondo nosso discurso numa organização temático-estrutural de camadas tópicas, em que as mais abrangentes contêm outras, mais específicas e particularizadas, de modo que ao analista seja possível alcançar, na materialidade lingüística do texto, os segmentos tópicos - unidades discursivas que atualizam as propriedades do tópico.

É, em parte, em virtude de sua natureza escalar que a topicalidade é um princípio organizador do discurso, pois, se por um lado, visto de modo global, o tópico manifesta-se hierarquicamente em níveis mais ou menos particularizados, por outro, ao alcançar um nível de concretude - sua manifestação em segmentos textuais -, torna-se possível descrever seu "comportamento" na linearidade do discurso em termos de continuidade ou descontinuidade ${ }^{3}$.

\section{A NOÇÃO DE QUADRO TÓPICO (QT).}

Feitas estas considerações teóricas, passo agora à apresentação da noção de Quadro Tópico (QT). No que diz respeito à sua definição, Jubran et al. (2002:346) relatam que as "relações de interdependência entre os níveis hierárquicos de organização tópica dão origem a Quadros Tópicos (QT)", que são caracterizados pelas seguintes condições (i) “a centração num tópico mais abrangente (Supertópico - ST), que recobre e delimita a porção de discurso em que ele é focal"; (ii) "a divisão interna em co-constituintes (Subtópicos - SbT), situados numa mesma camada de organização tópica, na medida em que apresentam o mesmo teor de concernência relativamente ao ST que lhes é comum"; (iii) "subdivisões sucessivas no interior de cada tópico co-constituinte, de forma que um tópico pode vir a ser ao mesmo tempo ST ou SbT, se mediar uma relação de interdependência entre dois níveis não imediatos" (Jubran et al. 2002:346).

${ }^{2}$ Não é meu objetivo explorar detalhadamente a propriedade de centração tópica e seus traços definidores como proposto por Jubran et al. (2002). Recomendo, pois, ao leitor interessado, além deste, os seguintes trabalhos: Koch (1992, 2004); Pinheiro (2005); Brown \& Yule (1983) e Jubran (2006).

${ }^{3}$ C.f. Jubran et al. (2002). 
Cadernos de Estudos Lingüísticos 48(1) - Jan./Jun. 2006

Nesta perspectiva, o QT é entendido como recorte analítico em que o analista foca sua atenção no eixo hierárquico de organização tópica para analisar unidades que, em virtude deste recorte, serão classificadas como supertópico ou subtópico no interior do QT estabelecido:

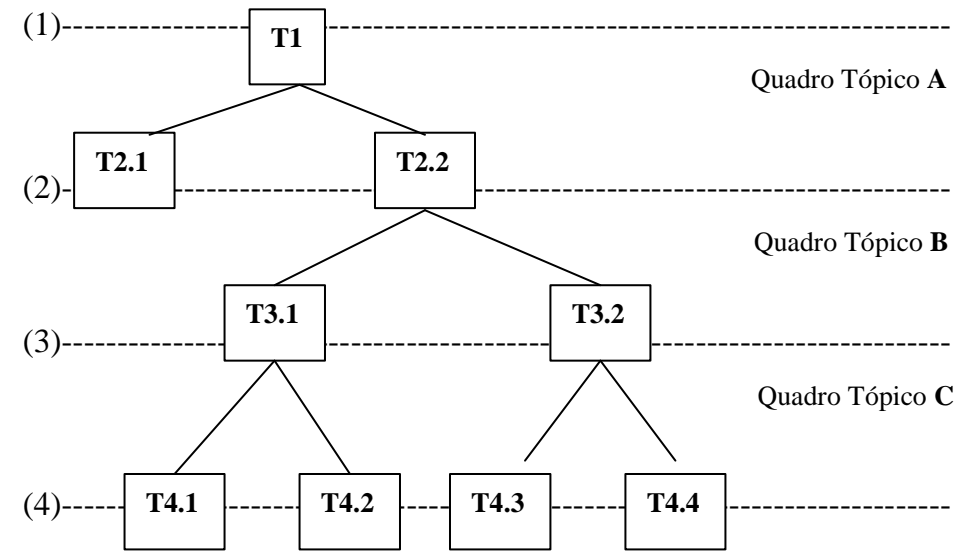

Observando o esquema acima, nos níveis (1) e (2), o tópico T1 funciona como supertópico em relação a T2.1 e T2.2 que, subordinados a ele, estão na condição de subtópicos, formando o quadro tópico A. Da mesma forma, se se atentar para a relação entre tópicos dos níveis (2) e (3), tem-se o quadro tópico B, no qual T2.2 é o supertópico, e ao qual se ligam os subtópicos T3.1 e T3.2 (este, se relacionado aos subtópicos T4.3 e T4.4, é o supertópico do QT C). Para Jubran et al. (1992) o QT é caracterizado em termos especificamente relacionais: trata-se de um procedimento metodológico de que se vale o analista para indicar quais são os tópicos subordinadores e quais os subordinados. Não se propõe, neste modelo, caracterizar o QT como um patamar da organização hierárquica tópica, mas como locus analítico que circunscreve tópicos de níveis diferentes, porém próximos.

Já Koch (1992:72) postula que um texto é passível de ser dividido em fragmentos recobertos por um mesmo tópico. A autora explica que os fragmentos textuais, quando agrupados, constituem uma unidade de nível mais alto, que, por sua vez, em conjunto com outras de mesmo nível, constituem outra unidade em nível superior, e assim sucessivamente. De modo que se denomina "aos fragmentos de nível mais baixo de segmentos tópicos; um conjunto de segmentos tópicos formará um subtópico; diversos subtópicos constituirão um quadro tópico; havendo ainda um tópico superior que englobe vários tópicos, ter-se-á um supertópico". Vejase o diagrama: 


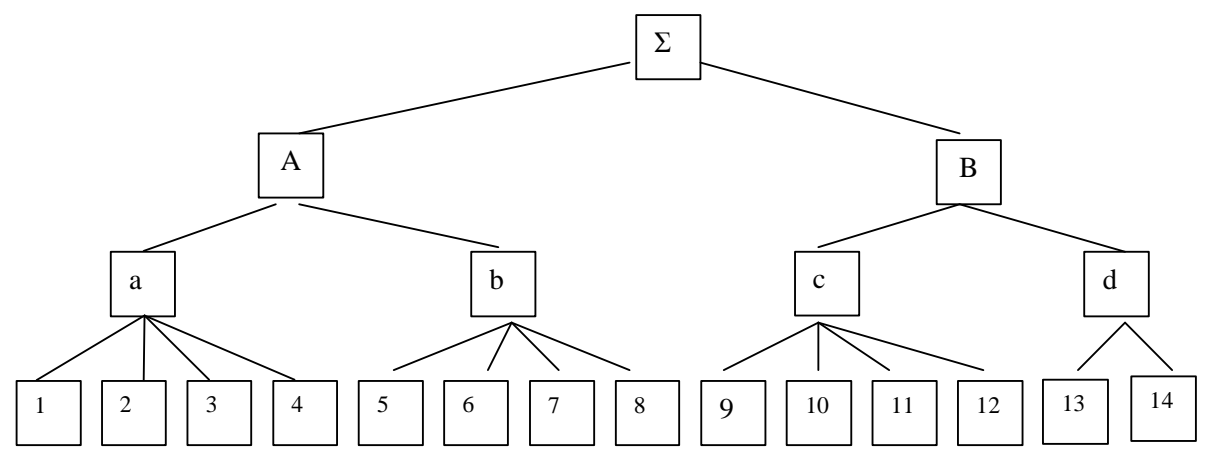

$$
\begin{array}{cc}
1 \text { a } 14 \text { = segmentos tópicos } & \mathrm{A}-\mathrm{B}=\text { quadros tópicos } \\
\mathrm{a}-\mathrm{b}-\mathrm{c}-\mathrm{d}=\text { subtópicos } & \Sigma=\text { supertópico }
\end{array}
$$

Ambos os modelos apresentam o tópico em níveis mais ou menos abrangentes e interdependentes entre si, prevendo uma organização hierárquica em camadas, de forma que a delimitação de fronteiras entre tópicos de níveis diferentes se dá segundo a abrangência do assunto em foco. A diferença entre eles fica evidente na medida em que para Koch (1992) o quadro tópico é definido como um nível de organização intermediária entre o tópico global do texto e outro nível mais específico de organização, o dos subtópicos, o nível mais próximo da materialização lingüística da unidade tópica, a saber, os segmentos tópicos; enquanto que, em Jubran et al. (1992) o QT, como já dito, é estritamente relacional.

Em Fávero (1993) tem-se uma terceira leitura. A autora entende que a "noção de verticalidade [a hierarquia tópica] refere-se às relações de interdependência que se estabelecem entre os tópicos de acordo com a menor ou maior abrangência do assunto e permitem dizer que há níveis na estruturação dos tópicos, indo desde um constituinte mínimo - subtópico (SbT) até porções maiores - tópicos (T) ou supertópicos (ST), constituindo um Quadro Tópico" (c.f. Fávero, 1993: 46-47), como se pode observar:

\section{QUADRO TÓPICO}

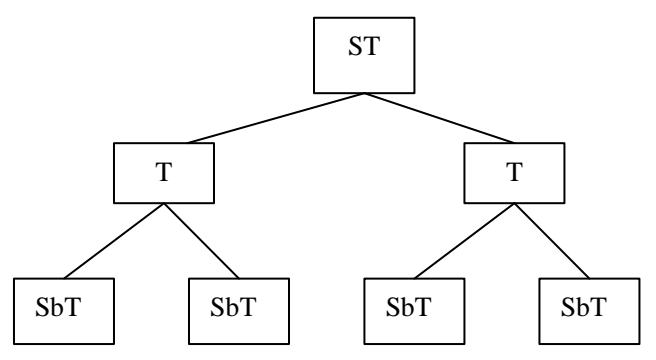


Cadernos de Estudos Lingüísticos 48(1) - Jan./Jun. 2006

O modelo acima proposto prevê, a exemplo de Koch (1992), um nível intermediário entre o subtópico e o supertópico, aqui denominado tópico. Mas diferentemente de Jubran et al. (1992) e de Koch (1992), QT para a autora é o panorama hierárquico geral, a disposição de todos os níveis tópicos.

Como afirmado no início deste artigo, não tenho qualquer pretensão de exaurir a questão - não é este o objetivo. No entanto, considero de suma importância a apresentação, ainda que breve, destas diferentes propostas de QT (e, conseqüentemente, de estruturação do eixo hierárquico de organização tópica), dada a quantidade de trabalhos que herdaram estas diferentes concepções: Fávero (1999); Koch (2002; 2004); Kronka (2003); Penha Lins (2004); Pinheiro (2005); Rezende (2005); Jubran (2006) e Koch \& Elias (2006). Assim, por ora parece-me válido perguntar se, do ponto de vista analítico, haveria consequiências entre as diferentes concepções e, em havendo, quais seriam.

Em minha análise da Sexta narrativa das Relações, de Heleno Godoy, adoto a noção de QT postulada em Koch (1992). Compreendo o QT como um importante nível de organização textual que, mesmo subordinado ao supertópico proposto pelo narrador (o qual denomino Vida da Protagonista), colabora na organização da matéria textual, dividindo a narrativa analisada em núcleos de subtópicos. Vejamos a seguir o eixo de organização hierárquica dessa narrativa: 
Vida da protagonista

\begin{tabular}{|c|c|c|}
\hline Quadros Tópicos & Subtópicos & Segmentos tópicos \\
\hline \multirow{13}{*}{ Casamento (evento) } & \multirow{4}{*}{ Negociação } & 1.caracterização do noivo \\
\hline & & 2.participação do futuro sogro \\
\hline & & 3.opinião/argumentação do pai \\
\hline & & 4.insensibilidade do noivo \\
\hline & \multirow[t]{2}{*}{ Vestido } & 5.preparação do vestido \\
\hline & & 6. escolha do vestido \\
\hline & \multirow{5}{*}{ Cerimônia } & 7. entrada na capela \\
\hline & & 8. juramento \\
\hline & & 9. troca de alianças \\
\hline & & 10. saída da capela \\
\hline & & 11. avaliação do sogro \\
\hline & \multirow[t]{2}{*}{$1^{a}$ noite nupcial } & 12. postura do marido \\
\hline & & 13. presença do sogro \\
\hline \multirow{6}{*}{ Casamento (cotidiano) } & \multirow[t]{2}{*}{ Vida sexual regular } & 14. repetitividade \\
\hline & & 15. envelhecimento do esposo \\
\hline & \multirow{4}{*}{ Vida doméstica } & 16. ficar na loja com o esposo \\
\hline & & 17. cuidar dos filhos/casa \\
\hline & & 18. ser cortejada/elogiada \\
\hline & & 19. mandonismo do sogro \\
\hline \multirow{8}{*}{ Traição } & \multirow{4}{*}{ Amor } & 20. descoberta do farmacêutico \\
\hline & & 21. atração \\
\hline & & 22. consumação do amor \\
\hline & & 23. filho bastardo \\
\hline & \multirow{4}{*}{ Reclusão religiosa } & 24. ir a igreja e sofrer agressão \\
\hline & & 25. críticas sociais \\
\hline & & 26. silêncio às críticas \\
\hline & & 27. trancar-se em casa \\
\hline
\end{tabular}




\section{A DISTRIBUIÇÃO TÓPICA NA SEXTA NARRATIVA}

Antes ainda de entendermos a organização tópica da Sexta narrativa, é preciso conhecer sua história: a de uma mulher, que, obrigada a se casar, suporta uma existência penosa (ao lado de seu marido medíocre e seu sogro autoritário) numa cidade interiorana, tendo como único alívio a descoberta do amor num caso extra-conjugal com o farmacêutico. Mas é preciso, principalmente, que o leitor conheça o aspecto central de Relações, a saber, a distinção enunciativa entre as vozes narrativas dos oito textos que compõem a obra, para só assim compreender que cada voz narrativa, mediante o trabalho que efetua sobre a progressão tópica, marca sua singularidade com relação ao que narra e, principalmente, com relação a como narra ${ }^{4}$.

No caso da Sexta a organização tópica é trabalhada mediante o uso inserções do narrador que avaliam, explicam os tópicos em desenvolvimento, ou ainda, inserções que antecipam tópicos futuros (Koch, 1997) ${ }^{5}$, tendo como objetivo pulverizar a ordem cronológica dos acontecimentos. A junção destes procedimentos cria então, à medida que a história progride, uma engrenagem narrativa fragmentária, em que tópicos se alternam, confundindo o leitor; em que se esboçam alguns tópicos (antecipando seu conteúdo ao leitor) a serem plenamente desenvolvidos posteriormente; ou ainda, em que alguns segmentos tópicos são atravessados por comentários e inserções do narrador, de inegável valor interativo-argumentativo, e que, certamente, interferem no seu desenvolvimento linear contínuo.

Mundo narrado e a enunciação que o institui estão inter-relacionados de modo que na superfície lingüística do texto obtenha-se um trabalho de progressão tópica descontínua - a engrenagem a que me refiro - que objetiva fazer, por um lado, com que o leitor "experimente", nas poucas páginas que lê, a vida desgastante (e a falta de perspectiva de dela se libertar) vivida pela protagonista ${ }^{6}$. Afinal, como explica Maingueneau (1996:154), a "enunciação da obra, longe de flutuar acima do mundo que exibe, deve dele participar".

Por outro lado, que o leitor, como corolário da própria atividade enunciativa em curso, atente para a instância narrativa, que chama a atenção para si própria, seja para (na obra como um todo), diferenciar-se dos demais narradores; seja para (na própria narrativa), diferenciarse dos personagens, apresentando-se como uma figura que não partilha suas cobranças com a protagonista. Ao contrário, defende-a contra "tudo aquilo que exigiam dela". Vejamos:

\section{Excerto 1}

exigiam dela e de seu corpo e cansaço, o que ela não tem para dar: que eles possam pedir compreensão, seria normal, e até relativo; que eles possam pedir conformação, nem seria necessário, e até inútil, sua vida tinha sido isso desde o dia em que o conhecera, ou ele a conhecera? [1 feio e fraco, dominado pelo pai, minúsculo perto dele 1], [2 que era quem mais falava ou só quem falava e falava por ele, combinava detalhes, fazia projetos 2], e ela se sentia como mercadoria a ser vendida, negociada: que ele pudesse vir a ser seu marido, afinal nem lhe indagaram se ela o queria ou se ela o aceitava, [3 isso não tinha importância nem estava incluído entre os pensamentos

${ }^{4}$ Em entrevista, o escritor Heleno Godoy afirmou ter concebido a obra com diferentes narradores para que o leitor visse "[...] cada aspecto do livro de um modo diferente, sem cair na mesmice de uma só focalização [...] Ao criar uma multiplicidade de pontos de vista ou de narradores, cada vez tento propiciar uma emoção nova [...] Cada narrador cria uma emoção diferente no leitor, apenas não nos esqueçamos de que, para cada uma haverá uma razão diferente. E são essas razões diferentes que eu quero que o leitor perceba". (c.f. Rezende, 2005).

\footnotetext{
${ }^{5}$ Ver a classificação de Koch (1997).
}

${ }^{6}$ Ver a narrativa em anexo. 
REZENDE - O tópico discursivo em questão...

de seu pai, que ele gostava das coisas em seus lugares onde achava que podia colocá-las, que filha é para isso mesmo, casar, ter filhos e não desonrar o marido nem o nome que tem (...) e você deve até se sentir feliz de que ele queira se casar com você (...) você não tem muita escolha, não pode decidir 3], pois até nisso eles a despersonalizavam, de agora em diante ela iria fazer parte da loja do sogro \& filho \& cama do filho, satisfazendo-lhe mais que suas vontades e as suas não eram contadas [4 e ele nem poderia pensar que elas existissem, se é que algum dia passou pela cabeça dele que elas, as suas vontades, pudessem existir, pouco ou nada lhe importaria em se preparar, aceitá-lo, vir até a sala onde seu noivado era planejado, olhá-lo como pela primeira vez 4], [2 olhar o sogro, entender que seu casamento seria mais com ele que com o filho 2], [5 sendo outras as sua preocupações daí em diante, como, por exemplo, sua mãe dizia, tirar medida para o vestido e os outros 5]

Já início do texto, no primeiro trecho em itálico, que não classifico como de natureza tópica, mas como um comentário avaliativo introdutório, a voz narrativa não só expõe a condição da protagonista (de não dispor de meios para libertar-se de sua submissão), mas reprova a maneira como os demais personagens a tratam. Atente-se para a intervenção avaliativa "e ela se sentia como mercadoria [...]: afinal nem lhe" (em itálico), que avalia o conteúdo do segmento tópico 2.participação do futuro sogro. Se como explica Koch (2004:132) a força argumentativa de "afinal" reside em obter a concordância do leitor/interlocutor com relação a uma idéia apresentada em um enunciado anterior, nessa inserção, o articulador "afinal" (sublinhado) é empregado de modo a induzir o leitor - pelo ponto de vista do pai, cuja voz surge no segmento 3.opinião/argumentação do pai - a enxergar entre as duas orações por ele articuladas a idéia de inevitabilidade daquele consórcio.

Veja-se ainda a inserção avaliativa "pois até nisso eles a despersonalizavam" (após o segmento 3). Introduzida pelo uso do articulador discursivo-argumentativo "pois", é de fundamental valor para a argumentação do narrador em favor da protagonista e contra a ação dos outros personagens. Aqui é contestada a argumentação do pai; o emprego de "pois" mostra que, se para o pai a filha simplesmente "não pode decidir", para o narrador trata-se de um ato de despersonalização. Despersonalizada, reificada, portanto, "de agora em diante", ela se tornaria um artigo a mais da "loja do sogro \& filho". Mediante o uso do articulador espácio-temporal "de agora e diante" (Koch, 2004), que atesta a sincronia da voz narrativa com o momento da negociação do consórcio, o narrador antecipa - o terceiro trecho em itálico no excerto - os segmentos tópicos 14. repetitividade e 16. ficar na loja com o esposo - constituindo uma inserção antecipadora de tópico futuro ("de agora em diante ela iria fazer parte da loja do sogro \& filho \& cama do filho”).

Ora, dadas as inserções que avaliam ou antecipam tópicos futuros, fica patente no excerto um teor reprovativo com relação à vida a que a protagonista foi submetida. A bem da verdade, difundido no texto como um todo, este teor é sobretudo perceptível na maneira rápida com que a voz narrativa promove mudança de centração de tópicos no trabalho de elaboração da progressão tópica. É como se o narrador, em seu discurso sobre a vida da personagem, atribulado e azafamado, mimetizasse uma vida nas mesmas condições. Veja-se, no começo do excerto 1 , que, quando começa a se desenvolver o segmento tópico 1.caracterização do noivo, a voz narrativa muda o foco de seu olhar instaurando nova centração e, conseqüentemente, o segmento 2.participação do futuro sogro. Se neste caso a articulação tópica se efetua em virtude da passagem do objeto de discurso (doravante OD) "sogro" de um segmento a outro, nota-se, ao fim do excerto, que a passagem do segmento tópico 4.insensibilidade do noivo ao segmento 2. participação do futuro sogro - e a passagem deste ao segmento 5. preparação do vestido 
- é feita pela justaposição destes tópicos, sem a presença de qualquer OD a efetuar a passagem entre os segmentos.

Como conseqüência de sua colaboração para a descontinuidade tópica, estes procedimentos - o deslocamento espacial e temporal na história (pela antecipação de segmentos tópicos); a postura de um narrador que critica e avalia o que narra e que explora o mundo interior das personagens (sobretudo o da principal) - estes procedimentos operam na construção do ethos narrativo. Constituem-se como recursos do narrador para sua argumentação paulatina, segundo a qual a traição será cometida não como um ato adrede, mas como um desabafo inevitável. Vejamos, no início da cerimônia ${ }^{7}$ do casamento, mais um pouco do desenvolvimento destes processos:

\section{Excerto 2}

[7 dando agora os primeiros passos já dentro da pequena capela que seu bisavô ajudara a construir, em direção ao altar onde ele esperava por ela, ao lado o padre e o pai 7], [13 e ela pensava que até no quarto, seu e dele, na que seria sua primeira noite, o pai haveria de estar presente 13] [8 e estar dizendo sim, que o aceitava, que o amaria, respeitaria, seria fiel 8], mas jamais passou pela sua cabeça que estar jurando tudo isso seria jurar em falso, porque era sua intenção amá-lo e respeitálo, ser-lhe fiel, dar-lhe filhos e amar esses filhos, educá-los, era o que ela mais queria e faria tudo para que assim fosse e, se não foi, ali, naquela hora, ela não poderia saber, não poderia saber que tudo o que jurara não aconteceria: deixar de amá-lo, respeitá-lo poucas vezes, traí-lo, e o mais que acarretava esse casamento que não era o que ela sonhava ou com o qual sonhara, é isso, ela estava destinada a qual outro? (...), afinal haveria outra saída? que outro homem poderia estar ali no lugar dele a seu lado, agradecendo presença e presentes, tanta gente no que seria sua alegria festejada e eram mais temores seus em esperar e ver o que poderia acontecer: por exemplo, não passaria nunca pela sua cabeça desejar que o velho, pai e sogro, morresse e, depois, de que adiantaria? ela teria que carregar para sempre o peso daqueles dois, o velho \& $o$ filho, a loja, os filhos, seu tudo, existência pequena, resistência pouca, ela era muito jovem para que a negociassem como agora, [9 agora tendo sentido aquelas mãos sobre as suas, a aliança sendo colocada em seu dedo, sua mão pequena, a esquerda e frágil, 9]

No início deste excerto vemos a repetição de um procedimento de articulação de segmentos tópicos, neste caso, os segmentos 7. entrada na capela e 13. presença do sogro, feita por um OD que transita de um tópico ao outro (o "sogro").

Em sua quase totalidade, o excerto 2 se caracteriza pela suspensão do desenvolvimento de tópicos. Em função de um movimento digressivo (o trecho em itálico no excerto), o narrador, após o brevíssimo desenvolvimento do segmento 8. juramento, abandona seu lugar próximo à personagem para deslocar-se para um outro ponto distante da ação (marcado pelos articuladores espaço-temporais "ali" e "naquela hora") de onde adota a perspectiva psicológica interna à protagonista e argumenta em favor da limitação da personagem em desconhecer o futuro ("ela não poderia saber").

Considerando-se que este é um momento crucial na vida da personagem - o instante do juramento de fidelidade - entendo que esta digressão, mais do que ligar os segmentos $\mathbf{8}$. juramento e 9. troca de alianças, atua como uma estratégia interativa do narrador em criar um anti-clímax: já na segunda página sabemos do fracasso que seria aquele casamento.

O articulador "mas" (sublinhado acima, após segmento 8) além de atestar a limitação da personagem em prever o que aconteceria, sela o fracasso do juramento feito; abre-nos o futuro que se antepõe, e se impõe, aos desejos da personagem, antecipando-nos o quadro tópico

\footnotetext{
${ }^{7}$ Por questões de espaço, avanço na análise sem me dedicar ao sub-tópico vestido.
} 
REZENDE - O tópico discursivo em questão...

"Traição", ("deixar de amá-lo, respeitá-lo poucas vezes, traí-lo") a ser desenvolvido posteriormente no texto.

Nota-se em toda a digressão que a voz narrativa intensifica sua argumentação em favor da inocência da protagonista ao questionar a inevitabilidade daquele casamento: "ela estava destinada a qual outro? (...) haveria outra saída? Mais do que isso: eram inelutáveis as consequiências futuras do consórcio, ter de "carregar para sempre o peso daqueles dois, o velho \& o filho, a loja, os filhos". Novamente são antecipados segmentos tópicos, neste caso 16. ficar na loja com o esposo e 17. cuidar dos filhos/casa, ainda a serem desenvolvidos na narração.

Porém, mesmo com o anti-clímax estabelecido, é a própria atividade enunciativa que se encarrega de manter vivo o interesse do leitor pela história. Um dos procedimentos a que recorre narrador para tal é a manutenção de sua postura avaliativa, ao caracterizar o futuro da personagem - "existência pequena, resistência pouca" -, ao inserir diretamente sua opinião, a inserção avaliativa: "ela era muito jovem para que a negociassem como agora" (último trecho sublinhado no excerto).

Mas o recurso à repetição é também acionado. No excerto 3 , é mediante a repetição do advérbio "agora" que a narração, após todo este movimento digressivo, é abruptamente centrada no instante da entrada na igreja:

\begin{abstract}
Excerto 3
ela era muito jovem para que a negociassem como agora, [9 agora tendo sentido aquelas mãos sobre as suas, a aliança sendo colocada em seu dedo, sua mão pequena, a esquerda e frágil, 9] [12 o ter que empurrá-lo depois, a dor lá em baixo, ela bem sabia que seria assim: tímido e apressado, ele nem procuraria saber de seu prazer ou dor, era direito dele, feio, magro e peludo sobre seu corpo branco, suas lágrimas, o suor e o sangue, quantas vezes aquelas estocadas 12], [9 e tocada ela estava naquele momento em que sua outra mão, a direita, segurava o ramo de flores de pano branco e o padre fazia uma cruz no ar 9], [13 aquele som abafado do outro lado da parede era ele, o velho, ela bem podia adivinhar, deitado e ressonando, escutando, invadindo seu corpo, 13] [12 não o filho, que esse era apenas um prolongamento dele, como sempre fora 12] [16 e era agora, sentado no tamborete de couro cru, a velha construção de mil novecentos e nove, que ainda era a mesma, a loja que fora do velho, a mesma posição, o mesmo cruzar de pernas 16], [14 que as suas se abriam e deviam recebê-lo ao menos três vezes por semana durante o que seria seus pouco mais de vinte e poucos anos de casada e frustração seguida 14] [10 e, em seguida, sair dali em linha reta, seu braço no dele, já casados 10], [11 e o velho é que fazia cara de orgulhoso e satisfeito 11]
\end{abstract}

Outros usos do advérbio "agora" são significativos no excerto 3, marcando o movimento do narrador sobre o eixo do tempo. A cada vez que "agora" é empregado, a enunciação coincide com o momento da ação, isto é, o narrador aproxima-se espacial e temporalmente daquilo que narra e nos traz consigo para assistirmos de perto a estes acontecimentos. Já os articuladores lógico-semânticos ("depois", "naquele momento", "em seguida") ordenam temporalmente os segmentos tópicos que, como se nota, não seguem qualquer sequiência lógica: da noite nupcial (segmentos 12. postura do marido e 13. presença do sogro) somos conduzidos ao cotidiano enfadonho, seja na loja (16.ficar na loja), seja na vida sexual da personagem (14.repetitividade) e, pela repetição de uma palavra ("seguida"), retornamos abruptamente ao momento da finalização da cerimônia (segmentos 10. saída da capela e 11.avaliação do sogro).

No começo do excerto 3 observa-se ainda o fenômeno alternância tópica entre os segmentos 9. troca de alianças e 12. postura do marido, que se revezam na linha discursiva. Cabe perguntar: que efeito narrativo se obtém desta alternância? Além de mostrar uma quase 
Cadernos de Estudos Lingüísticos 48(1) - Jan./Jun. 2006

simultaneidade entre estes fatos, a primeira noite nupcial, alternando com a consumação do sacramento, prenuncia como será a desagradável e repetitiva (na ótica da personagem e do narrador) vida sexual da personagem, a ser reiterada pela introdução e desenvolvimento do segmento tópico 14. repetitividade (da vida sexual). Note-se, no entanto, que antes mesmo deste segmento, o segmento 16.ficar na loja surge na linha discursiva, enfatizando a idéia de repetitividade. Neste caso, da repetição do modo de vida do sogro pelo filho.

Neste sentido, a imagem do segmento 9. troca de alianças, a aliança colocada no dedo daquela mão "esquerda e frágil", simboliza a inserção definitiva da personagem no círculo vicioso de uma vida sexual maçante e sem prazer; de uma vida cotidiana apresentada como repetitiva ("a loja que fora do velho, a mesma posição, o mesmo cruzar de pernas") e que a narrativa, pela sua construção, imita.

Essa idéia de um círculo vicioso que permeia a narrativa (e a constitui) é reiterada, no excerto 4, pela reativação dos segmentos tópicos 16. ficar na loja com o esposo, 14. repetitividade da vida sexual e pelo aparecimento do segmento tópico 17. cuidar dos filhos/ casa, consequiência do segmento 14:

\section{Excerto 4}

[10 e, em seguida, sair dali em linha reta, seu braço no dele, já casados 10] [11 e o velho é que fazia cara de orgulhoso e satisfeito, não pela nora, mas em ver o filho casado e levando a mulher para casa, ali mesmo, perto, ao redor da igreja, 11] [24 a mesma capela que ela passaria a freqüentar sempre, depois que tudo aconteceu, depois que toda a cidade sabia, ali. refúgio e fuga, sua fita da irmandade do santíssimo no pescoço, ali também ela não teria paz 24], [16 que paciência ela sempre teve, paciência para agüentá-lo todos os dias, feio e fraco, trabalhando na loja o dia todo, 16] [19 enquanto o pai tecia suas manobras políticas, mandando indagar quem era que tinha chegado na cidade, o que tinha vindo fazer 19] era isso mesmo seu sogro, [19 e ele se orgulhava disso, tirava partido e mandava, expulsava pessoas do lugar, sentia-se dono da rua, da praça, da casa, do filho, 19] [14 aquele que dormia a seu lado, usava-a com certa regularidade, os filhos vindo com regularidade também, 14] até quando isso duraria? era a indagação que ela fazia, [20 só que a resposta, mesmo vindo na forma de outro homem magro que não era feio e nem controlado pelo pai, teria que esperar por mais tempo 20], [17 o seu de tomar conta dos filhos, ajudá-los a crescer, vesti-los, entregá-los ao avô \& ao pai, do primeiro ao último 17], [23 e um deles não seria dele e ele não sabia nem nunca ficaria sabendo o que a cidade toda sabia e comentava 23], [18 afinal, ela seria também fraca o suficiente para se deixar levar, no futuro, pelos elogios que receberia por sua beleza 18]

Além deste aspecto, a significação no excerto é construída principalmente em função da articulação e desenvolvimento de tópicos pertencentes a quadros tópicos diferentes, distantes no eixo hierárquico. Veja-se, para citar um exemplo do excerto, a articulação dos segmentos 11. avaliação do sogro e 24. ir à igreja e sofrer agressão, promovida pela passagem do OD "igreja" de um segmento a outro. A articulação de segmentos pertencentes a quadros tópicos distintos reforça a não linearidade cronológica característica da narrativa.

\section{A CONSTRUÇÃO DO ETHOS NO TEXTO}

Retomo novamente a base teórica do sub-grupo da "Organização textual-interativa", segundo a qual o texto é uma unidade de interação verbal e social situada em contextos espaçotemporais e sócio-históricos, e em cuja materialidade são projetadas as estratégias interacionais dos sujeitos. Com base nesta concepção, e para os fins pretendidos neste trabalho, entendo o 
REZENDE - O tópico discursivo em questão...

ethos $^{8}$ como efeito de sentido caracterizador da voz narrativa a partir de seu trabalho sobre o discurso, passível de ser percebido pelo leitor na materialidade lingüística do texto, tal como o define Maingueneau (2002):

\begin{abstract}
Não se trata de uma representação estática e bem delimitada, mas antes, de uma forma dinâmica, construída pelo destinatário através do próprio movimento de fala do locutor. $\mathrm{O}$ ethos não age no primeiro plano, mas de maneira lateral, ele implica uma experiência sensível do discurso, mobiliza a afetividade do destinatário [...] A eficácia do ethos depende do fato de que ele envolve qualquer tipo de enunciação sem ser explicitado no enunciado.
\end{abstract}

Se para a retórica grega a ethé era entendida como as propriedades que os oradores em praça pública conferiam a si próprios ao discursarem com objetivos persuasivos, não afirmando diretamente sinceridade ou franqueza, mas, enunciando de modo a transparecer tais atributos, Maingueneau mantém vivo esse aspecto enunciativo da noção. Na medida em que prevê a existência de um interlocutor (na tentativa de fazê-lo aderir a um ponto de vista) o autor entende o fenômeno do ethos como noção dialógica, efeito de sentido construído discursivamente no desenvolver das interações entre os sujeitos pela presença do outro, que ouve, que sente afetivamente $-\mathrm{o}$ discurso sobre si.

Neste sentido, o "movimento de fala" mencionado por Maingueneau (2002) pode ser entendido como o movimento de progressão tópica que se desenvolve na seqüencialidade da narrativa analisada, haja vista que a disposição dos tópicos neste eixo, diferentemente do texto falado, depende unicamente do narrador. Além disso, o movimento dos tópicos no texto implica uma experiência sensível do discurso, como afirma Maingueneau, causando no leitor certo impacto. A narrativa não teria o mesmo efeito se não fosse narrada como é.

Nesta narrativa, o trabalho sobre a progressão tópica pode, portanto, ser caracterizado por um trabalho de progressão descontínua dos segmentos tópicos em três frentes: (i) devido à presença de inserções que interferem no desenvolvimento linear contínuo de boa parte dos segmentos, mas que integram o trabalho argumentativo do narrador; (ii) devido à rápida mudança de centração dos segmentos tópicos (dada a presença de algum OD que transita de um a outro) conferindo à narração um ritmo acelerado, e às ações narradas um efeito de atribulação; finalmente, (iii) devido à articulação de segmentos pertencentes a quadros tópicos distintos, marcando a não linearidade cronológica da narrativa.

Estes procedimentos desenvolvidos pelo narrador integram-se na construção de sua argumentação em prol da inocência da personagem, mas, e principalmente, se desdobram na constituição de uma imagem que o narrador quer transparecer, a de alguém repleto de compaixão, caracterizando seu ethos de compaixão, portanto.

No entanto, (e eis o ardil da beleza do texto) este ethos manifesta-se sob outra caracterização, como se observa no segmento tópico 22. consumação do amor:

\footnotetext{
${ }^{8} \mathrm{O}$ conceito de ethos nunca foi claro e unívoco. Auchlin (2001), por exemplo, entende que a dificuldade de definição do ethos se dá em função do grau de variação com que o termo é empregado, o que faz com que este seja visto menos como uma noção teórica precisa e mais como uma noção prática. Nosso interesse neste trabalho será a noção de ethos segundo postulado por Aristóteles em sua Retórica. Como explica Auchlin (2001), o ethos é caracterizado por certa lubricidade [labilité] conceitual, seja em retórica, em pragmática, ou ainda em estilística, sendo concebido como "mais ou menos dialogal (Vs. monologal), mais ou menos focal (Vs. enquadrante), mais ou menos moral (Vs. técnico), mais ou menos convencionalizado (Vs. emergente), mais ou menos intradiscursivo (Vs. mundando), mais ou menos abstrato (Vs. Concreto, carnal)".
} 


\section{Excerto 5}

[22 e ele era mais que isso subindo até seus lábios que ele circundava, alvo e alga, até se diluir, metálico, em seus braços ao redor de seu corpo e copo, aquelas mãos nela e em seus seios sobre o peito dele, largo e lago onde, planta, seu banhar encontrava uma ilha naquela verdade, luz e solicitude, geografia relativa, suas mãos tangendo seu corpo eram mais que aquele amor, distância e presença, a dualidade de tantos membros que mais de dois eram os dois e mãos à sua volta, ela voltando para casa depois, vindo do quintal, vindo lá do fundo do quintal, quantas vezes, à noite, ela sairia da cama e casa para ir ao fundo do quintal, quantas vezes ele ficaria até mais tarde na farmácia e pularia o muro que a separava dele, quantas vezes alguém da farmácia veria que ele saía e pulava o muro? 22] [26 não, nada disso ela diria, ela ficaria quieta, ouvindo o que lhe diziam ao telefone 26]

Conforme explica Maingueneau (1995:153), o fenômeno do ethos evidencia "a dimensão analógica da comunicação literária" (grifo do autor). Se neste segmento assistimos ao único momento de beleza da vida da protagonista, momento no qual a personagem não é despersonalizada, este efeito é alcançado em grande parte pelas aliterações dos fonemas /a/, /v/ , /w/, /g/, /k/, /o/, e /p/. Através deste recurso o narrador mais do que conta um momento lírico, enuncia-o de modo poético; traz para a enunciação, sob uma roupagem que até então não empregara, sua ternura pela personagem. A traição, em virtude de como é enunciada, se converte, de pecado, em um gesto de amor, sublimação e auto-reconhecimento.

\section{CONSIDERAÇÕES FINAIS}

Meus objetivos neste trabalho foram dois. Um, restrito à primeira parte deste artigo, foi o de apresentar as diferenças entre as noções de QT existentes na bibliografia sobre o tópico discursivo. Acredito que a diferença dos modelos, em autoras participantes de um mesmo grupo, é reveladora do próprio fazer científico. E, assim sendo, é possível agora lançar (em trabalhos posteriores) o questionamento destas diferenças. Quais seriam as consequiências teóricas e analíticas que a escolha de um modelo específico encerra? Como cada um poderia ser aperfeiçoado?

Meu segundo objetivo: eleger um modelo proposto e, a partir dele, observar a movimentação tópica numa narrativa literária na tentativa de entender a construção de um fenômeno discursivo. Ressalto que a análise desenvolvida não é definitiva, bem como o modelo é passível de ser aprimorado. No entanto, à guisa de exercício analítico e reflexão teórica, é preciso destacar que, nos moldes como está feita, parece-me uma boa vereda a se trilhar na investigação sobre os efeitos de sentido obtidos no/pelo trabalho com a progressão tópica em narrativas escritas.

\section{REFERÊNCIAS BIBLIOGRÁFICAS}

AUCHLIN, A. (2001). "Ethos et expérience du discours: quelques remarques". In : M. Et A. C. Simon (éds). Politesse et idéologie. Rencontres de pragmatique et de réthorique conversationnelles. Louvain, Peeters, "BCILL", 77-95.

FÁVERO, L. L. (1993). "O tópico conversacional”. In: PRETI, D. (org.) Análise de textos orais. São Paulo: FFLCH/USP. pp.33-54. 
REZENDE - O tópico discursivo em questão...

FÁVERO, L. L. (1999). "O tópico discursivo". In: PRETI, D. (org.) 4 ed. Análise de textos orais. São Paulo: Humanitas Publicações FFLCH/USP.pp. 33-54.

GODOY, H. (1993). Relações. Goiânia: Editora da UCG, $2^{\text {a }}$ Edição. Prêmio Bolsa de Publicações "Hugo de Carvalho Ramos".

JUBRAN, C.C.A.S et al. (2002). "Organização tópica da conversação". In: ILARI, R. (org.). Gramática do português falado, vol. II. Campinas, SP: Editora da UNICAMP.

. (2006). Tópico discursivo. Em: Clélia Cândida Abreu Spinardi Jubran e Ingedore Grunfeld Villaça Koch (Orgs.). Gramática do Português Culto Falado no Brasil. Campinas: Editora da UNICAMP, vol. I - Construção do texto falado, pp. 89-132.

KOCH, I.G.V. (1992). Inter-ação pela linguagem. São Paulo: Contexto. (1997). O texto e a construção dos sentidos. São Paulo: Contexto. (2002) Desvendando os segredos do texto. São Paulo: Cortez. (2004) Introdução à lingüística textual. São Paulo: Martins Fontes.

KOCH, I.G.V. \& ELIAS, V.M. (2006). Ler e compreender os sentidos do texto. São Paulo: Contexto.

KRONKA, G.Z. (2003). "Análise do discurso e Lingüística Textual: um diálogo possível”. Campinas/SP: IELUNICAMP (Texto de qualificação - Doutorado). Mimeo.

MAINGUENEAU, Dominique.(2002). "L'ethos, de la réthorique à l'analyse du discours". In: Pratiques, n 113-114, juin 2002 (Version raccourcie et légèrement modifiée de «Problèmes d'ethos»). Disponível na página pessoal do autor: http://perso.wanadoo.fr/dominique.maingueneau/. Acesso em 10/11/2005. . (1995). O contexto da obra literária. São Paulo: Martins Fontes.

PAREDES SILVA, V.L. (1995). “Ao correr da pena: aspectos da organização tópica em cartas pessoais”. In: HEYE, J. (org.). Flores verbais. Rio de Janeiro, Ed. 34.

PENHA LINS, M. (2004). Organização tópica do discurso de tiras diárias de quadrinhos. Rio de Janeiro: Tese de Doutorado (UFRJ).

PINHEIRO, C. L. (2005). Estratégias textuais-interativas: a articulação tópica. Maceió: EDUFAL.

REZENDE, R.C. (2005). Ethos e progressão textual: a construção lingüístico-discursiva do ethos dos narradores de Relações, de Heleno Godoy. Campinas: Dissertação de Mestrado - IEL/UNICAMP. 